\title{
Plantas Daninhas Hospedeiras Alternativas de Colletotrichum guaranicola EM Cultivos de GuARANÁ no Estado do Amazonas ${ }^{1}$
}

\author{
Alternative Host Weeds of Colletotrichum guaranicola in Guarana Crops in the State \\ Amazonas
}

MILÉO, L.J. ${ }^{2}$, SILVA, J.F. ${ }^{3}$, BENTES, J.L.S. ${ }^{4}$ e CHRISTOFFOLETI, P.J. ${ }^{5}$

\begin{abstract}
RESUMO - As plantas daninhas reduzem a produção de sementes de guaraná e podem hospedar microrganismos patogênicos, tornando-se potenciais fontes de inóculo. Este trabalho identificou espécies de plantas daninhas colonizadas pelo fungo Colletotrichum guaranicola em cultivos de guaranazeiro em quatro municipios do Estado do Amazonas. As plantas daninhas foram identificadas e a presença do fungo foi verificada por meio de isolamentos feitos a partir de fragmentos de folhas lesionadas. As espécies colonizadas por C. guaranicola foram Bidens bipinnata, Chloris sp., Clidemia capitellata, Cyperus flavus, Elephantopus scaber, Euphorbia brasiliensis, Hemidiodia sp., Hyptis lantanifolia, Paspalum conjugatum, Physalis angulata e Synedrella nodiflora, as quais podem representar uma fonte de inóculo do patógeno, além das plantas de guaraná. A diversidade de plantas daninhas, em cultivos de guaranazeiro, reforça a importância de estabelecer práticas de manejo dessas plantas, principalmente em Maués, onde ocorreu maior colonização das espécies de plantas daninhas pelo fungo.
\end{abstract}

Palavras-chave: infestação, guaranazeiro, mancha foliar, hospedeira.

\begin{abstract}
Weed infestation may reduce grain guarana crops yield and host plant pathogens becoming potential inoculum sources. This research identified weed species colonized by the fungus Colletotrichum guaranicola in the guarana crop in four counties in the state of Amazon. The weeds were identified fungi presence was observed by isolation from leaf fragments of leaves injured by the fungi. The weed species colonized by Colletotrichum guaranicola were Bidens bipinnata, Chloris sp., Clidemia capitellata, Cyperus flavus, Elephantopus scaber, Euphorbia brasiliensis, Hemidiodia sp., Hyptis lantanifolia, Paspalum conjugatum, Physalis angulata and Synedrella nodiflora, that may represent a strong potential of plant pathogen inoculum, along with the guarana plants. Weed diversity in guarana crop shows the importance of establishing management practices to control these weeds, mainly in the Maues county, where higher colonization of the weed plants by the fungi was observed.
\end{abstract}

Keywords: infestation, guarana plant, leaf spot, host.

1 Recebido para publicação em 15.4.2007 e na forma revisada em 29.11.2007.

2 Professora Assistente, M.Sc., Universidade Federal do Amazonas. Rua 1 de Maio, S/N - Bairro da Colônia, 69.630-000Benjamim Constant, AM, <libiamileo@ufam.edu.br>; ${ }^{3}$ Prof. Associado, Dr., Universidade Federal do Amazonas. Av. Gen. Rodrigo Octávio Jordão Ramos, 3000, Setor Sul do Campus Universitário. 69077-000, Manaus, AM, <jfsilva@ufam.edu.br>; ${ }^{4}$ Professora Dra., Universidade Federal do Amazonas. Av. Gen. Rodrigo Octávio Jordão Ramos, 3000, Setor Sul do Campus Universitário. 69077-000, Manaus, AM < jlbentes@ufam.edu.br>; ${ }^{5}$ Prof. Associado do Dep. de Produção Vegetal da Escola Superior de Agricultura "Luiz de Queiroz" - ESALQ/USP, Caixa Postal 09, 13419-900 Piracicaba-SP, <pjchrist@esalq.usp.br>. 


\section{INTRODUÇÃO}

O Brasil é o único país produtor de guaraná (Paullina cupana em escala comercial. No Estado do Amazonas, em 2003 a área cultivada foi de 5.178 ha, com produção de 779 toneladas de sementes secas (IBGE, 2006). Nesse Estado, a infestação de plantas daninhas tem limitado a expansão do cultivo do guaraná devido à forte interferência sobre a cultura (Coutinho et al., 1999). Isso ocorre em razão da alta diversidade de espécies e do elevado número de Poaceaes tropicais, principalmente no município de Maués-AM (Albertino et al., 2004).

Outro efeito deletério das plantas daninhas na produtividade do guaranazeiro está associado à ação indireta, quando essas plantas hospedam microrganismos patogênicos para a cultura (Mileo et al., 2006). As plantas daninhas que ocupam extensas áreas tornam-se potenciais fontes de inóculo de fitopatógenos em cultivos comerciais, desempenhando papel fundamental na epidemiologia das doenças como hospedeiras secundárias (Chaves et al., 2003).

Estudos conduzidos por Batista (1984) constataram plantas daninhas freqüentes em cultivos de guaranazeiro, como hospedeiras do fungo Colletotrichum guaranicola, agente da antracnose do guaranazeiro, a principal doença da cultura (Albuquerque, 1961; Trindade \& Poltronieri, 1997). Esta doença tem sido apontada como responsável pela redução da área cultivada com guaraná no Estado do Amazonas (IBGE, 1999), podendo levar à redução de até $88 \%$ das plantações, em condições de cultivo tradicional, e, com isso, inviabilizar a exploração do guaranazeiro como alternativa econômica dos produtores (Araújo et al., 2002).

A infestação de plantas daninhas, em cultivos de guaranazeiro, pode ocasionar o aumento da colonização natural das invasoras suscetíveis pelo patógeno, em condições de campo. Esse fato reforça a importância de conhecer as plantas associadas ao fungo para estabelecer medidas de controle da doença, por meio do manejo das plantas daninhas, possibilitando assim a redução do inóculo inicial do patógeno no campo, em guaranazais da região.

Este trabalho teve por objetivo identificar plantas daninhas hospedeiras do fungo Colletotrichum guaranicola em sistemas de pro- dução de guaranazeiro, em quatro municípios do Estado do Amazonas.

\section{MATERIAL E MÉTODOS}

\section{Áreas de coleta}

As coletas das plantas daninhas foram realizadas no período de agosto a novembro de 2004, durante a estação seca, em áreas de cultivo de guaranazeiro, nos municípios de Iranduba, Maués, Presidente Figueiredo e Manaus-AM, totalizando seis áreas de coleta, de acordo com a Tabela 1.

Nas propriedades de pequenos produtores, o sistema de produção não apresentava uso de adubo e a roçagem das plantas daninhas era realizada com facão, uma vez por ano, com mão-de-obra familiar. Os grandes produtores possuiam sistema de produção tecnificado, com plantio de clones, adubação e mão-de-obra assalariada. Os plantios de guaraná tinham idades superiores a oito anos, exceto o de Presidente Figueiredo.

\section{Amostragem}

A amostragem das plantas daninhas foi feita conforme o método descrito por Velini (1994). Em cada local de coleta, foi selecionada uma área de cerca de 1 ha, onde foram demarcadas duas linhas transversais, em formato de X, e na qual foram feitas as coletas, utilizando-se um quadrado de madeira de 0,60 x 0,60 m, arremessado 20 vezes ao acaso sobre as linhas, totalizando 20 amostras por área de coleta. A cada arremesso, as plantas que estavam dentro do quadrado foram cortadas rente ao solo, acondicionadas em sacos plásticos e transportadas para o Laboratório de Ciência das Plantas Daninhas da Faculdade de Ciências Agrárias da UFAM, onde foram quantificadas e selecionadas para os estudos seguintes.

\section{Identificação das plantas daninhas coletadas}

Para identificação das espécies, foram retiradas amostras de cada planta, prensadas e colocadas para secar em estufa a $75^{\circ} \mathrm{C}$, durante 48 horas, e depois montadas em exsicatas e identificadas por classe, família, gênero e 
Tabela 1 - Locais de coleta de plantas daninhas em cultivos de guaranazeiro em quatro municípios do Amazonas

\begin{tabular}{|c|c|c|c|}
\hline Município & Propriedade & \multicolumn{2}{|c|}{ Coordenada geográfica } \\
\hline Iranduba & Antonio de Oliveira $\left(\mathrm{P}^{*}\right)$ & $\mathrm{S} 03^{\circ} 08^{\prime} 48^{\prime \prime}$ & W $60^{\circ} 11^{\prime} 06^{\prime \prime}$ \\
\hline \multirow{3}{*}{ Maués } & Raimunda de Lima (P) & $S\left(03^{\circ} 21^{\prime} 42^{\prime \prime}\right.$ & W $57^{\circ} 42^{\prime} 36^{\prime \prime}$ \\
\hline & Embrapa $\left(\mathrm{E}^{* *}\right)$ & $\mathrm{S} 03^{\circ} 23^{\prime} 39^{\prime \prime}$ & W $57^{\circ} 42^{\prime} 00^{\prime \prime}$ \\
\hline & Fazenda Santa Helena $\left(\mathrm{G}^{* * *}\right)$ & $\mathrm{S} 03^{\circ} 26^{\prime} 59^{\prime \prime}$ & W 57 38'09”' \\
\hline Presidente Figueiredo & Agropecuária Jayoro $(\mathrm{G})$ & S $01^{\circ} 57^{\prime} 51^{\prime \prime}$ & W 60' $13^{\prime} 49^{\prime \prime}$ \\
\hline Manaus & Fazenda da Ufam (E) & $\mathrm{S} 02^{\circ} 38^{\prime} 55^{\prime \prime}$ & W 60"03'09" \\
\hline
\end{tabular}

$* \mathrm{P}=$ pequeno produtor (menos de $4 \mathrm{ha}$ ); **E = área experimental; $* * * \mathrm{G}=$ grande produtor (maior que 50 ha).

espécie, comparando-se as características botânicas de cada espécime com as descritas na literatura (Kissmann \& Groth, 1997a, b, c; Lorenzi, 1994). Após a identificação foi calculada a freqüência das espécies, de acordo com Brandão et al. (1998), em que freqüência $=n^{\circ}$ de amostras que contêm a espécie/ $\mathrm{n}^{\circ}$ total de amostras obtidas.

\section{Isolamento e identificação de fungos associados às plantas daninhas}

Para isolamento dos fungos, foram selecionadas plantas que apresentavam sintomas de manchas foliares, das quais foram retirados fragmentos da área de transição entre a parte sadia e a lesionada. Estes foram desinfetados superficialmente com álcool a $70 \%$ e hipoclorito de sódio a $2 \%$ por um minuto, sendo depois lavados em água destilada e esterilizada por três vezes (Dhingra \& Sinclair, 1995). Em ambiente asséptico, os fragmentos desinfestados foram depositados em placas de Petri contendo o meio de cultura BDA (batata-dextrose-ágar) acrescido de antibiótico cloranfenicol (250 mg L-1), incubados a $28{ }^{\circ} \mathrm{C}$ durante 48 horas. Após esse período, os fungos que se desenvolveram foram repicados para novas placas, para individualização das colônias. Os isolados obtidos foram transferidos para tubos de ensaio com BDA inclinado e mantidos em laboratório até a identificação dos fungos. Para cada espécie de planta daninha prepararam-se duas placas de Petri, com cinco fragmentos de folha em cada placa.

\section{Identificação dos isolados de fungos}

Para identificação, em nivel de gênero, dos isolados fúngicos obtidos, foram confeccionadas lâminas para microscopia, contendo as estruturas reprodutivas e de infecção dos fungos, coloridas com azul de algodão em lactofenol, observadas em microscópio óptico e comparadas com as descrições das chaves para identificação de fungos (Hanlin, 1990; Carmichael et al., 1980; Barnett \& Hunter, 1970; Sutton, 1980).

As colônias fúngicas com características morfológicas de C. guaranicola foram selecionadas e observadas por meio de lâminas contendo estruturas reprodutivas (conídios). $\mathrm{Na}$ identificação da espécie do fungo foram adotados os critérios estabelecidos por Sutton (1980) e as dimensões descritas por Albuquerque (1961) e Bentes \& Barreto (2004), por meio de medições com auxílio de lâmina micrométrica, do comprimento e da largura de 50 conídios de cada isolado.

\section{RESULTADOS E DISCUSSÃO}

\section{Plantas daninhas coletadas em cultivos de guaranazeiro}

Foram coletadas 414 e identificadas 359 plantas, classificadas em 29 famílias e 73 espécies. O maior número de espécies de plantas daninhas foi encontrado na classe Magnoliopsida (56), representando aproximadamente $77 \%$ do total das espécies identificadas, coletadas nos quatro municípios, destacando-se os cultivos de guaranazeiro em Maués (Tabela 4). As outras espécies pertencem às classes Liliopsida (16) e Pteridófita (1). As outras amostras de plantas (55) não foram identificadas devido à ausência das estruturas reprodutivas necessárias para determinação das espécies.

A predominância de espécies da classe Magnoliopsida também foi encontrada por 
Albertino et al. (2004) quando estudaram a composição florística das plantas daninhas em cultivos de guaranazeiro, em cinco municipios do Amazonas, e constataram que, de 40 famílias identificadas, 35 pertenciam a Magnoliopsida. De acordo com Nee (1995), o elevado número de famílias de Magnoliopsida é atribuído à diversidade de plantas existentes desta classe. Para Deuber (1992), a predominância de Magnoliopsida sobre Liliopsida pode estar relacionada ao número de famílias - mais de 40 no Brasil - de importância econômica. Sousa (1995) menciona que as famílias de plantas daninhas da classe Magnoliopsida possuem muitas espécies agressivas.

A família Asteraceae apresentou diversidade de plantas daninhas em cultivo de grande produtor, em Maués, devido ao número de espécies (7) e à ocorrência nos quatro municípios amostrados. Essa família é importante em número de espécies e agressividade (Kissmann $\&$ Groth, 1997). Espécies de Asteraceae foram freqüentes em levantamentos de plantas daninhas em ambientes antropizados (Carneiro \& Irgang, 1999), em pastagens naturais (Quadros et al., 2003), em cultivos de arroz irrigado (Erasmo et al., 2004) e em pomares de goiabeira (Barbosa et al., 2003), por se encontrarem presentes durante todo o ano no campo. Lorenzi (2000) afirma que espécies de Asteraceae estão entre as primeiras plantas daninhas que surgem no campo após o preparo do solo para plantio.

A família Euphorbiaceae, segunda em número de espécies (6), registrou a maioria das plantas daninhas em cultivo de grande produtor, em Maués. Segundo Kissmann \& Groth (1997b), a família Euphorbiaceae possui cerca de 5.000 espécies, e o gênero Euphorbia, mais de 700. Em levantamento de plantas daninhas em cultivos de girassol, Euphorbiaceae destacou-se em número de espécies e Euphorbia heterophylla, com um dos mais altos indices de importância (Brighenti et al., 2003).

As famílias Bignoniaceae, Fabaceae, Rubiaceae, Solanaceae e Verbenaceae apresentaram espécies em três municípios.

$\mathrm{Na}$ classe Liliopsida, a família Poaceae apresentou diversidade de plantas daninhas nos quatro municipios. No Brasil, a classe Liliopsida possui seis famílias com mais de
60 espécies de plantas daninhas, sendo a maioria perene (Deuber, 1992). Devido à diversidade e capacidade de adaptação, as gramíneas estão entre as mais agressivas plantas daninhas e, como forrageiras, são absolutamente dominantes (Kissmann \& Groth, 1997a). Em áreas de pastagem, no município de Vassouras (RJ), a família Poaceae também apresentou o maior número de espécies de plantas daninhas (Peixoto et al., 1982).

A família Poaceae, junto com Asteraceae, possui maior número de espécies em ambientes antropizados, como demonstraram os trabalhos de Gavilanes \& D'Angieri Filho (1991) e Pedrotti \& Guarim Neto (1998). No Estado do Amazonas, em cultivos de guaranazeiro, representantes dessas duas famílias apresentaram-se em maior número de espécies de plantas daninhas (Albertino et al., 2004), e, no Pólo Juazeiro/Petrolina, a família Poaceae.

Segundo Deuber (1992), a maioria das espécies de Poaceae é perene e produz grande quantidade de sementes, o que favorece a disseminação e o estabelecimento em determinada área. Assim, a alta ocorrência de Poaceae pode indicar a maior eficiência das espécies na exploração dos fatores de crescimento, podendo isso também ser atribuído ao manejo e, possivelmente, à diminuição da fertilidade do solo (Silva et al., 1988; Kissmann \& Groth, 1997b).

Cyperaceae foi a segunda família mais representativa da classe Liliopsida, com maior diversidade de espécies na área experimental da Ufam em Manaus (6). Essa família possui cerca de 220 espécies de plantas daninhas que ocorrem com intensidade em muitas regiões, e aproximadamente $42 \%$ pertencem ao gênero Cyperus (Deuber, 1992; Kissmann \& Groth, 1997a). As espécies têm ampla distribuição, desenvolvendo-se em ambientes variados e em solos de baixa fertilidade, o que pode justificar sua presença nos cultivos de guaranazeiro, conforme verificado neste trabalho.

Na classe Pteridófita identificou-se a família Dennstaediaceae, com a espécie Pteridium aquilinum, coletada em cultivos de pequeno e grande produtor, em Iranduba e Presidente Figueiredo, respectivamente. A espécie é freqüente em regiões de solos ácidos e de baixa 
fertilidade, não sendo problema em solos cultivados porque a correção da acidez do solo inviabiliza seu desenvolvimento (Lorenzi, 2000). Segundo Albertino et al. (2004), a baixa freqüência de $P$. aquilinum em cultivos de guaranazeiro pode estar associada às características do solo das áreas de plantio, os quais apresentaram variação de $\mathrm{pH}$ entre 4,21 e 5,51, cujos valores classificam estes solos como moderadamente ácidos (Tomé Júnior, 1997).

Quanto à freqüência (Tabela 2), as espécies com os maiores indices foram Paspalum conjugatum, Panicumlaxum, Digitaria horizontalis e Cyperus flavus. Freire et al. (1988) relataram $P$. conjugatum entre as dez plantas daninhas freqüentes em cultivos de guaranazeiro, no sudeste da Bahia, adaptadas às condições de baixa luminosidade e aos solos de fertilidade média (Lisboa \& Vinha, 1982). As espécies Euphorbia brasiliensis, Hyptis lantanifolia, Rhynchospora nervosa e Solanum rugosum apresentaram indice de freqüência de $10 \%$ cada. Estas espécies não ocorreram em todos os municipios, exceto em Maués, onde todas foram coletadas. As outras espécies apresentaramse com freqüência inferior a $10 \%$. Homolepis aturensis, embora tenha apresentado indice de freqüência menor que $10 \%$ (Tabela 4), foi encontrada nos quatro municipios amostrados. Albertino et al. (2004) verificaram ampla distribuição desta espécie, em cultivos de guaranazeiro, em cinco municípios do Estado do Amazonas .

No tocante à distribuição das plantas daninhas por municipio, a maioria das 73 espécies ocorreu em Maués, seguida por Ufam-Manaus, Iranduba e Presidente Figueiredo (Tabela 2). Algumas espécies foram restritas para determinado municipio e outras ocorreram em mais de um deles. A presença de mesma espécie em dois ou mais locais indica a dispersão dela na área amostrada (Albertino et al., 2004). A distribuição das espécies pode ter sido influenciada pela topografia, umidade do solo, drenagem, compactação e fertilidade do solo, sendo esta última uma das mais importantes (Häusler \& Nordmeyer, 1995).

A variação das espécies de plantas daninhas pode ser explicada pelas diferentes formas de manejo usadas em cada sistema de produção, conforme observado nas propriedades de pequenos e grandes produtores. As plantas daninhas variam sua composição florística em função do tipo e da intensidade de tratos culturais impostos, tornando-se fundamental reconhecer essas espécies (Erasmo et al., 2004). Outro fator associado à variação das plantas daninhas é o banco de sementes, considerado a reserva de sementes e propágulos vegetativos tanto em profundidade quanto em superficie (Roberts, 1981). Assim, os diferentes sistemas de manejo do solo devem condicionar as sementes a microambientes, alterando as propriedades físico-químicas e a superficie do solo (Mulugueta \& Stoltemberg, 1997).

A infestação dos cultivos por plantas daninhas pode ser atribuida ao manejo, considerando que há escassez de mão-de-obra na área de produção, e o controle manual torna-se mais dificil em função das condições climáticas de alta temperatura, umidade relativa do ar e densa radiação solar (Silva, 1999). Além disso, a mão-de-obra para os trabalhos de capina aumenta os custos da produção (Coutinho et al., 1999). Possivelmente, a falta de capinas regulares permite a convivência das plantas daninhas com o guaranazeiro durante praticamente todo o ciclo produtivo.

\section{Fungos associados às plantas daninhas}

Nas seis áreas cultivadas com guaranazeiro foram identificadas 47 espécies de plantas daninhas colonizadas por diferentes fungos, cujo isolamento resultou em 1.009 isolados fúngicos identificados por classe e gênero (Tabela 3), compreendendo a maioria por gêneros não-patogênicos para a cultura do guaraná.

As plantas daninhas Bidens bipinnata, Clidemia capitellata, Cyperus flavus, Euphorbia brasiliensis, Hemidiodia sp., Hyptis lantanifolia, Physalis angulata, Elephantopus scaber, Synedrella nodiflora, Chloris sp. e Paspalum conjugatum foram colonizadas, entre outros fungos, pelo Colletotrichum guaranicola, agente da principal doença do guaranazeiro (Tabela 4).

Essas espécies vêm sendo encontradas com freqüência nos guaranazais do Estado do Amazonas (Albertino et al., 2004), sendo uma fonte alternativa de sobrevivência para o patógeno.

A colonização das plantas daninhas pelo C. guaranicola confirmou a interação patógeno- 


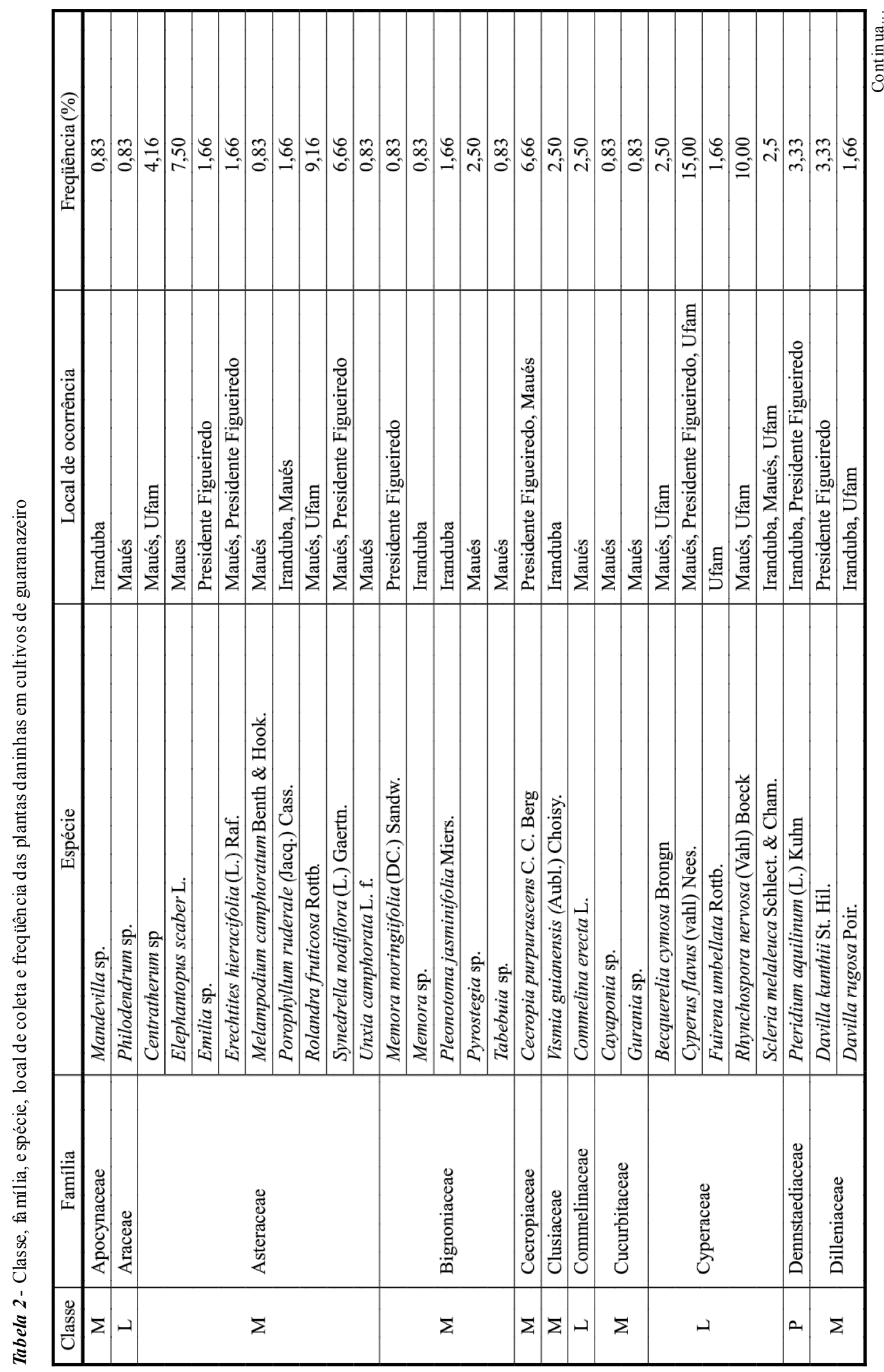




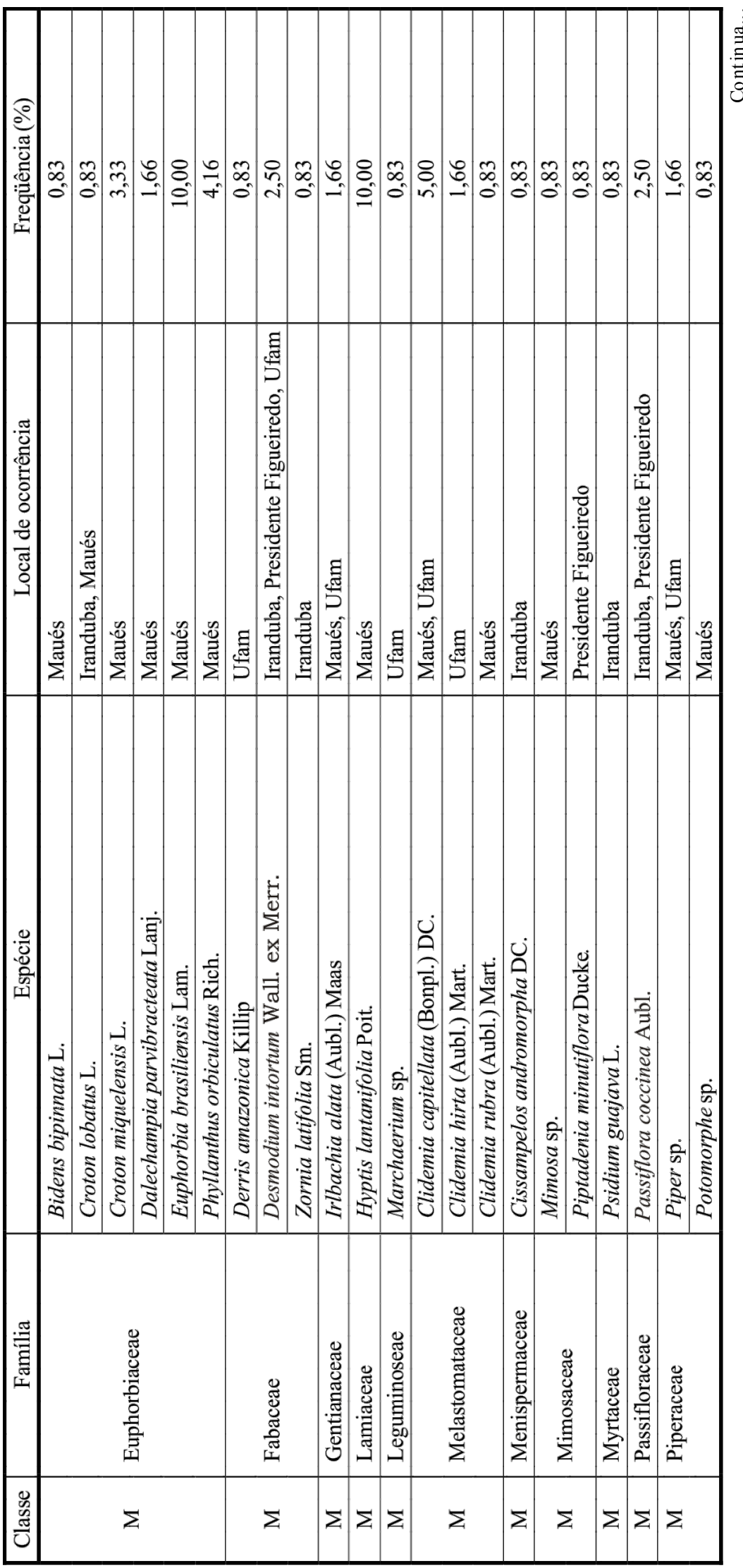




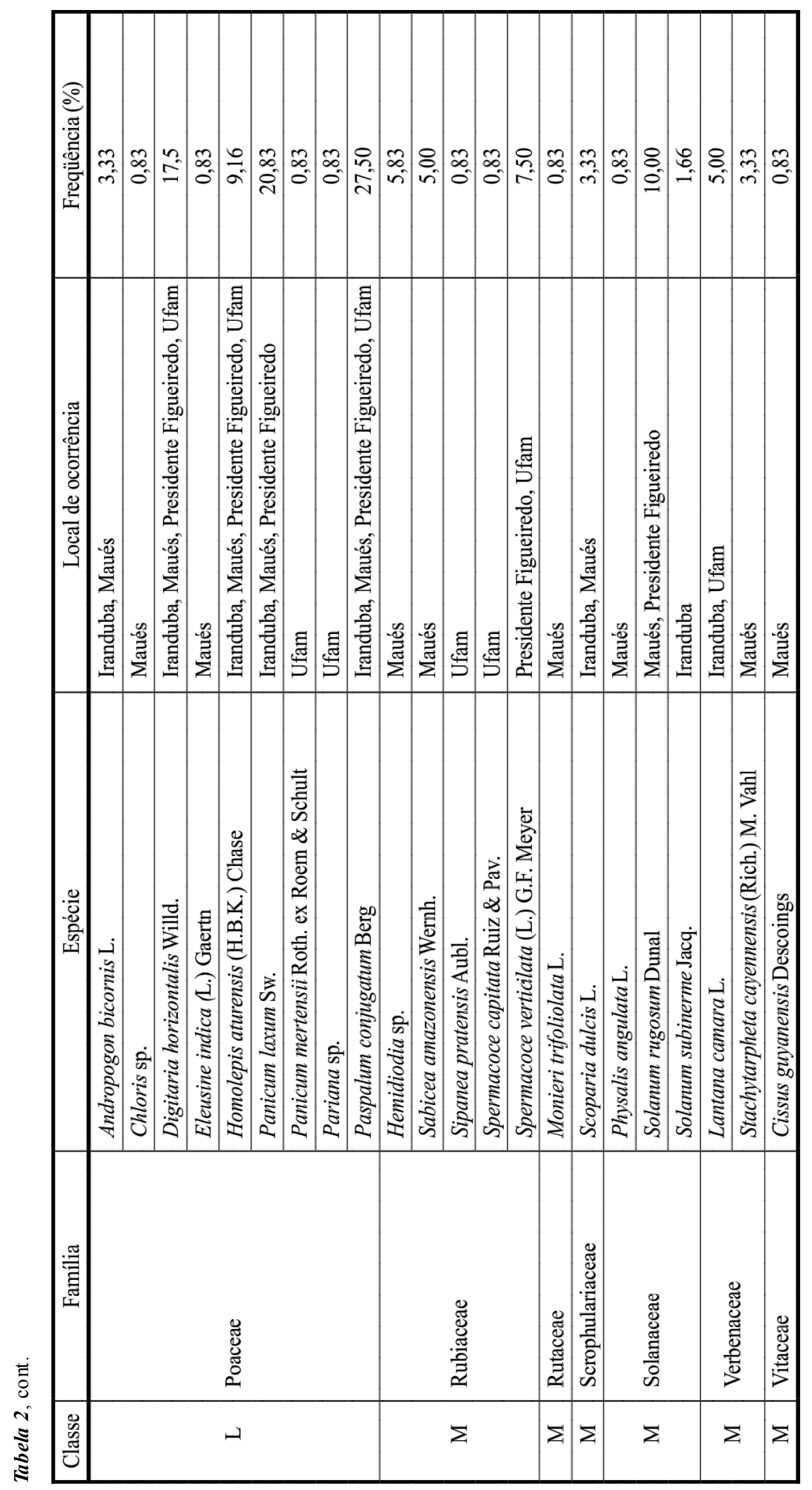


Tabela 3 - Classe, gênero e número de isolados de fungos obtidos a partir de plantas daninhas coletadas em cultivos de guaranazeiro

\begin{tabular}{|c|c|c|}
\hline Classe & Gênero & $\mathrm{N}^{\mathrm{o}}$ de isolados \\
\hline Ascomycetes & Chaetomium & 19 \\
\hline \multirow{8}{*}{ Coelomycetes } & Botryodiplodia & 25 \\
\hline & Colletotrichum & 30 \\
\hline & $\begin{array}{l}\text { Colletotrichum } \\
\text { guaranicola }\end{array}$ & 51 \\
\hline & Diplodia & 7 \\
\hline & Pestalotiopsis & 190 \\
\hline & Phoma & 4 \\
\hline & Phomopsis & 103 \\
\hline & Phomopsis lantanae & 9 \\
\hline \multirow{11}{*}{ Hyphomycetes } & Apergillus & 46 \\
\hline & Beltramia & 14 \\
\hline & Cordana & 5 \\
\hline & Curvularia & 93 \\
\hline & Fusarium & 149 \\
\hline & Nigrospora & 5 \\
\hline & Paecilomyces & 3 \\
\hline & Penicillium & 235 \\
\hline & Sclerococoum & 5 \\
\hline & Trichoderma & 9 \\
\hline & Verticillium & 3 \\
\hline Zygomycetes & Rhizopus & 4 \\
\hline Total & & 1.009 \\
\hline
\end{tabular}

hospedeiro entre as espécies suscetiveis e o fungo. Contudo, a existência dessa interação havia sido demonstrada por Batista (1984) a partir da inoculação de plantas daninhas, coletadas em cultivos de guaranazeiro com o fungo da antracnose, as quais se comportaram como hospedeiros do patógeno. No presente trabalho foi verificada a colonização natural das plantas daninhas pelo fungo e constatada a presença de diferentes espécies daquelas encontradas anteriormente, indicando a suscetibilidade a outras espécies que ocorrem em guaran azais.

A diversidade de plantas daninhas foi demonstrada por espécies distintas distribuídas nos guaranazais, observando-se também a presença de representantes de ciclo anual e perene (Tabela 4). Além disso, constatou-se a predominância de plantas da classe
Magnoliopsida, que compreende espécies de plantas daninhas consideradas muito agressivas (Sousa, 1995). Essa conjugação de eventos pode elevar o nivel de infestação existente na maioria dos cultivos, sobretudo em Maués, onde estavam presentes todas as plantas daninhas colonizadas pelo fungo.

As plantas daninhas hospedeiras de C. guaranicola pertencem a diferentes familias botânicas, destacando-se Asteraceae, Euphorbiaceae e Poaceae. As es pécies Elephantopus scaber e Synedrella nodiflora da familia Asteraceae estão entre os hospedeiros naturais do patógeno da antracnose. As espécies Bidens bipinnata e Euphorbia brasiliensis da família Euphorbiaceae foram colonizadas naturalmente pelo patógeno da antracnose. Esta família destaca-se pelo número de espécies invasoras em cultivo de girassol (Brighenti et al., 2003). As espécies Chloris sp. e Paspalum conjugatum, da família Poaceae, também foram colonizadas pelo agente da antracnose em cultivos de guaranazeiro. Constatou-se a presença dessa espécie, em plantios de cacau e bananeira, entre as infestantes de maior ocorrência. Em outros trabalhos com plantas daninhas, na região amazônica, a espécie $P$. conjugatum está entre as mais freqüentes (Souza et al., 1998). As espécies Paspalum conjugatume Synedrella nodiflora, semelhante aos cultivos do Estado do Amazonas, ocorrem comumente em cultivos de guaraná, na região produtora da Bahia (Freire et al., 1988). A presença constante dessas espécies nos plantios, sobretudo na condição de hospedeiras do C. guaranicola, talvez possa colaborar para o aumento da intensidade da antracnose.

A colonização natural das plantas daninhas por C. guaranicola evidencia espécies suscetiveis ao fungo, potenciais fontes de inóculo e de disseminação da antracnose em área com cultivos de guaranazeiro A presença desses hospedeiros alternativos parece garantir a sobrevivência do patógeno em condições de estação seca (Albuquerque, 1961). Com isso, os propágulos do fungo produzidos nesse período podem aumentar a quantidade de inóculo e, por conseguinte, o número de plantas doentes, principalmente na época chuvosa, mais favorável ao desenvolvimento da doença, ocasionando alta incidência da antracnose no campo 
Tabela 4 - Plantas daninhas hospedeiras de Colletotrichum guaranicola coletadas em diferentes áreas de cultivo de guaranazeiro no Estado do Amazonas

\begin{tabular}{|c|l|l|c|l|}
\hline Classe & \multicolumn{1}{|c|}{ Família } & \multicolumn{1}{|c|}{ Espécie } & Ciclo & \multicolumn{1}{c|}{ Local de coleta } \\
\hline M & Asteraceaee & Elephantopus scaber L. & Perene & Maués \\
\hline M & Asteraceae & Synedrella nodiflora (L.) Gaertn. & Anual & Maués, Pres. Figueiredo \\
\hline L & Cyperaceae & Cyperus flavus (Vahl) Nees. & Perene & Maués, Pres. Figueiredo, Ufam \\
\hline M & Euphorbiaceaee & Bidens bipinnata L. & Anual & Maués \\
\hline M & Euphorbiaceae & Euphorbia brasiliensis Lam. & Anual & Maués \\
\hline M & Lamiaceae & Hyptis lantanifolia Poit. & Perene & Maués \\
\hline M & Melastomataceae & Clidemia capitellata (Bonpl.) DC. & Perene & Maués, Ufam \\
\hline L & Poaceae & Chloris sp. & - & Maués \\
\hline L & Poaceae & Paspalum conjugalum Berg. & Perene & Iranduba, Maués, Pres.Figueiredo, Ufan \\
\hline M & Rubiaceae & Hemidiodia sp. & - & Maués \\
\hline M & Solanaceae & Physalis angulata L. & Anual & Maués \\
\hline
\end{tabular}

$\mathrm{M}=$ Magnoliopsida; $\mathrm{L}=$ Liliopsida .

(Duarte et al., 1981; Trindade \& Poltronieri, 1997).

A presença de plantas daninhas hospedeiras naturais do C. guaranicola reforça a necessidade da aplicação de práticas de manejo delas, sobretudo das espécies suscetiveis ao patógeno, em sistemas de produção do guaranazeiro, como meio de diminuir a incidência da antracnose em campo.

\section{LITERATURA CITADA}

ALBERTINO, S. M. F. et al. Composição florística das plantas daninhas na cultura de guaraná (Paullinia cupana), no Estado do Amazonas. Planta Daninha, v. 22, n. 1, p. 18, 2004.

ALBUQUERQUE, F. C. Antracnose do guaraná. Rio de Janeiro: Ministério da Agricultura. Serviço de Informação Agrícola, 1961. 22 p.

ARAÚJO, J. C. A. et al. Surto de antracnose (Colletotrichum guaranicola) do guaranazeiro (Paullinia cupana var. sorbilis) no Estado do Amazonas. Fitopatol. Bras., v. 27, p. 78, 2002. Suplemento.

BARBOSA, F. R. et al. Nível de dano, plantas invasoras hospedeiras, inimigos naturais e controle do psilídeo (Triozoida sp.) da goiabeira no submédio São Francisco. R. Bras. Frutic., v. 25, n. 3, p. 425-428, 2003.

BARNETT, H. L.; HUNTER, B. B. Illustred genera of imperfect fungi. 3.ed. Minneapolis: Burgess Publishing Company, 1970
BATISTA, M. F. Plantas silvestres hospedeiras de Colletotrichum guaranicola. In: SIMPÓSIO BRASILEIRO DO GUARANÁ, 1., 1984, Manaus. Anais... Manaus: Embrapa-UEPAE de Manaus, 1984. p. 409-411.

BENTES, J. L. S.; BARRETO, R. W. Reavaliação taxonômica de Colletotrichum guaranicola Albuq. agente causal da antracnose do guaranazeiro. Acta Amaz., v. 34, n. 1, p. 129-131, 2004.

BRANDÃO, M.; BRANDÃO, H.; LACA-BUENA, J. P. A mata ciliar do Rio Sapucaí-MG: fitossociologia. Daphane, v. 8, n. 4 , p. $36-48,1998$.

BRIGHENTI, A. M. et al. Cadastramento fitossociológico de plantas daninhas na cultura do girassol. Pesq. Agropec. Bras., v. 38, n. 5, p. 651-657, 2003.

CARMICHAEL, J. W. et al. Genera of Hyphomycetes. Alberta: The University of Alberta Press, 1980.

CHAVES, A. L. R. et al. Erigon bonariensis: hospedeira alternativa do lettuce mosaic vírus no Brasil. Fitopatol. Bras., v. 28, n. 3, p. 307-311, 2003.

CARNEIRO, A. M.; IRGANG, B. E. Colonização vegetal em aterro sanitário na região peri-urbana de Porto Alegre, RS, Brasil. R. Faculdade Zootec. Veter. Agron., v. 6, n. 1, p. 21-28, 1999.

COUTINHO, E. F. et al. Controle de plantas daninhas na cultura do guaranazeiro. Manaus: Embrapa, CPAA, 1999. p. 1-12. (Pesquisa em Andamento, 15)

DEUBER, R. Ciência das plantas daninhas: fundamentos. Jaboticabal: FUNEP, 1992. v. 1, 431 p. 
DHINGRA, O. D.; SINCLAIR, J. B. Basic plant pathology methods. 2.ed. Boca Raton: CRC, 1995. 434 p.

DUARTE, M. L. R.; CORRÊA, M. P. F.; ALBUQUERQUE, F. C. Epidemiologia da antracnose do guaranazeiro - freqüência da ocorrência em diferentes sistemas de produção. Fitopatol. Bras., v. 6, n. 6, p. 606, 1981.

ERASMO, E. A. L.; PINHEIRO, L. L. A.; COSTA, N. V. Levantamento fitossociológico das comunidades de plantas infestantes em áreas de produção de arroz irrigado cultivado sob diferentes sistemas de manejo. Planta Daninha, v. 22, n. 2, p. 195-201, 2004.

FREIRE, A. S.; PEREIRA, R. C.; SACRAMENTO, C. K. Efeito de herbicidas em plântulas de guaraná (Paullinia cupana var.sorbilis (Mart.(Ducke) e sobre as principais plantas daninhas ocorrentes na cultura. R. Theobroma, v. 18, n. 1, p. $67-81,1988$.

GAVILANES, M. L.; D’ANGIERI FILHO, C. N. Flórula ruderal da cidade de Lavras, MG. Acta Bot. Bras., v. 5, n. 2, p. 77-88, 1991.

HANLIN, R. T. Illustrate genera of Ascomycetes. 2.ed. St. Paul: The American Phytopathological Society, 1990. 324 p.

HÄUSLER, A.; NORDMEYER, H. Impact of soil on weed distribution. In: SEMINAR ON SITE SPECIFIC FARMING, 1995, Denmark. Resumos... Denmark: Institute for Weed Research, 1995. p. 186-189.

INSTITUTO BRASILEIRO DE GEOGRAFIA E ESTATÍSTICA - IBGE. Censo agrícola de 1999.

Disponível em: $<$ http://www.sidra.ibge.gov.br.>Acesso em: 19 de janeiro 2005.

INSTITUTO BRASILEIRO DE GEOGRAFIA E ESTATÍSTICA - IBGE. Censo agrícola de 2006.

Disponível em: $<$ http://www.sidra.ibge.gov.br. $>$ Acesso em: 20 de janeiro 2007.

KISSMANN, K. G.; GROTH, D. Plantas infestantes e nocivas. 2.ed. São Paulo: BASF Brasileira, 1997a. Tomo 1. $25 \mathrm{p}$.

KISSMANN, K. G.; GROTH, D. Plantas infestantes e nocivas. 2.ed. São Paulo: BASF Brasileira, 1997b. Tomo 2. $978 \mathrm{p}$.

KISSMANN, K. G.; GROTH, D. Plantas infestantes e nocivas. 2.ed. São Paulo: BASF Brasileira, 1997c. Tomo 3. $722 \mathrm{p}$.

LORENZI, H. Manual de identificação e controle de plantas daninhas: plantio direto e convencional. 4.ed. Nova Odessa: Plantarum, 1994. 299 p.

LISBOA, G.; VINHA, S. G. Plantas indesejáveis em cacauais de idades diferentes na área do Centro de Pesquisas do Cacau (CEPEC). R. Theobroma, v. 12, n. 3, p. 135-140, 1982.
LORENZI, H. Plantas daninhas do Brasil, terrestres, aquáticas, parasitas e tóxicas. 3. ed. Nova Odessa: Instituto Plantarum, 2000. 624 p.

MULUGUETA, D.; STOLTEMBERG, D. E. Increase weed emergence and seed bank depletion by soil disturbance in notillage systems. Weed Sci., v. 45, p.234-241, 1997.

NEE, M. Flora preliminar do Projeto Dinâmica Biológica de Fragmentos Florestais (PDBFF). New York: Botanical Garden, Manaus: INPA/Smithsonian, 1995. 264 p.

PEDROTTI, D. E.; GUARIM NETO, G. Flora ruderal da cidade de Cuiabá, Mato Grosso, Brasil. Acta Bot. Bras., v. 12, n. 2, p. 135-143, 1998.

PEIXOTO, A. L.; CARVALHO, S. M.; ROSA, M. M. T. Análise botânica de um campo de pastagem do Estado do Rio de Janeiro. Planta Daninha, v. 5, n. 2, p.1-7, 1982.

MILEO, L. J. et al. Plantas de cobertura de solo como hospedeiras alternativas de Colletotrichum guaranicola. Planta Daninha, v. 24, n. 4, p. 677-683, 2006.

QUADROS, F. L. F. et al. Levantamento das pastagens naturais da região de Santa Maria - RS, Brasil. Ci. Rural, v. 33, n. 5, p. 921-927, 2003.

ROBERTS, H. A. Seed banks in the soil. Adv.Appl. Biol., v. 6, n.1, p.1-55, 1981.

SILVA, L. A. M.; VINHA, S. G.; PEREIRA, R. C. Gramíneas invasoras de cacauais. Ilhéus: Comissão Executiva do Plano da Lavoura Cacaueira, 1988. 108 p. (Boletim Técnico, 159).

SILVA, J. F. Influência de herbicidas no crescimento e anatomia da epiderme foliar de cupuaçu (Theobroma grandiflorum (Willdenow ex Spreng) Schumann) e leguminosas em consorciação. 1999. 171 f. Tese (Doutorado em Botânica) - Instituto Nacional de Pesquisa da Amazônia, Manaus, 1999.

SOUSA, S. G. A. Dinâmica de plantas invasoras em sistemas agroflor estais implantados em pastagens degradadas da Amazônia Central (Região de Manaus AM). 1995. 97 f. Dissertação (Mestrado Recursos Florestais) - Escola Superior de Agricultura "Luiz de Queiroz”, Piracicaba, 1995.

SOUZA, G. F.; SILVA, J. F.; FIGUEIREDO, A. F. Levantamento de plantas daninhas em áreas com e sem cultivos, em Manaus - AM. R. Univ. Amaz., Série: Ci. Agrárias, v. 7, n. 1-2, p. 33-43, 1998.

SUTTON, B. C. The Coelomycetes. Surrey: Commonwelth Mycological Intitute, 1980. 696 p.

TOMÉ JÚNIOR, J. B. Manual para interpretação de análises de solo. Cuiabá: Agropecuária Guaíba, 1997, 247 p. 
TRINDADE, D. R.; POLTRONIERI, L. S. Doenças do guaraná. In: KIMATI, H. et al. (Eds.). Manual de fitopatologia: doenças das plantas cultivadas. 3.ed. São Paulo: Agronômica Ceres, 1997. p. 459-462.
VELINI, E. D. Estudo e desenvolvimento de métodos experimentais e amostrais adaptados a matologia. 1994. 250 f. Tese (Doutorado em Produção Vegetal) - Universidade Estadual Paulista Júlio de Mesquita Filho, Jaboticabal, 1994. 